\title{
Natural Astaxanthin From Haematococcus Pluvialis Enhanced Antioxidant Capacity And Improved Semen Quality In Aging Layer Breeder Roosters Through The Mitogen-Activated Protein Kinase/Nuclear Factor-Erythroid 2-Related Factor 2 (MAPK/Nrf2) Pathway
}

\author{
Shan Gao ( $\nabla 1197116620 @ q q . c o m$ ) \\ Beijing University of Agriculture \\ Nuo Heng \\ Beijing University of Agriculture \\ Fang Liu \\ Beijing University of Agriculture \\ Yong Guo \\ Beijing University of Agriculture \\ Yu Chen \\ Beijing General Station of Animal Husbandry \\ Liang Wang \\ Beijing University of Agriculture \\ Hemin Ni \\ Beijing University of Agriculture \\ Xihui Sheng \\ Beijing University of Agriculture \\ Xiangguo Wang \\ Beijing University of Agriculture \\ Kai Xing \\ Beijing University of Agriculture \\ Longfei Xiao \\ Beijing University of Agriculture \\ Xiaolong Qi \\ Beijing University of Agriculture
}

Research

Keywords: natural astaxanthin, semen quality, antioxidant capacity, MAPK/Nrf2 pathway, aging rooster

Posted Date: April 13th, 2021

DOI: https://doi.org/10.21203/rs.3.rs-408705/v1

License: @ (i) This work is licensed under a Creative Commons Attribution 4.0 International License. Read Full License 


\section{Abstract}

Background: Natural astaxanthin (ASTA) has strong antioxidant properties and has been widely used as a health product to improve human health. However, the effects of ASTA on the reproductive performance of aging roosters have been poorly studied. We aimed to investigate the effects of dietary ASTA on semen quality and antioxidant capacity in aging roosters and to explore the potential mechanism of semen quality change via anti-oxidation defense system.

Methods: In the present study, 96 53-week-old Jinghong No. 1 layer breeder roosters were fed a corn-soybean meal basal diet containing ASTA at $0,25,50$, or $100 \mathrm{mg} / \mathrm{kg}$ for 6 week.

Results: Semen quality in the ASTA groups remarkably improved as compared to those in the control group and antioxidant activities, the abilities to scavenge hydroxyl radicals and superoxide anions increased gradually with ASTA addition $(P<0.05)$. In addition, the mRNA levels of antioxidant enzymes, the mRNA and protein levels of the mitogen-activated protein kinase (MAPK), nuclear factor-erythroid 2-related factor 2 (Nrf2) were markedly increased in the 50-100 mg/kg ASTA group $(P<0.05)$.

Conclusions: Collectively, these results demonstrate that dietary ASTA may improve semen quality by increasing antioxidant enzyme activities, and the ability to scavenge hydroxyl radicals, which may be related to up-regulation of the MAPK/Nrf2 pathway.

\section{Introduction}

In poultry production, assisted reproductive technology such as artificial insemination is widely used. A single male is responsible for fertilizing dozens of female birds[1]. Therefore, the reproductive performance of roosters is a key factor in production. However, the sperm quality of roosters decreases gradually at approximately 50-55 weeks[2]. Several important reproductive traits change in aging roosters, including decreases in the sperm concentration, motility, testosterone level, and antioxidant capacity[3; 4]. Male fertility is one of the most important factors in determining hatchability. Therefore, it is necessary to find a way to alleviate the influence of age on the reproductive characteristics of breeding roosters. Recently, studies have shown that dietary supplementation with natural anti-oxidative compounds such as dietary linseed oil[5], lycopene[6] and curcumin[7] can alleviate the negative effects of age on roosters.

Astaxanthin (3,3-dihydroxy- $\beta$, $\beta$-carotene-4,4-dione) is a xanthophyll carotenoid, that is mainly divided into two forms: natural astaxanthin (ASTA) and synthetic astaxanthin. ASTA can be extracted from algae[8], yeast[9], fish, krill, and some microorganisms[10]. The microalgae Haematococcus pluvialis (a green microalga) is one of the major sources of ASTA, and can be extract a large amount of ASTA under stress conditions[12; 11]. Although synthetic astaxanthin has the same chemical formula as ASTA, the ability to scavenge singlet oxygen and free radical of ASTA is over 50 times and 20 times that of synthetic astaxanthin, respectively [13]. Meanwhile, the European Commission considers ASTA as a food dye[14]. Currently, ASTA has received much attention for its various beneficial characteristics, including its anti-oxidant[15], anti-inflammatory[16] and antiapoptotic properties[17]. However, there is little information on whether ASTA can improve the male reproductive performance.

The mitogen-activated protein kinase (MAPK) pathway, a family of serine/threonine protein kinases, is widely conserved in eukaryotes and is involved in antioxidant enzyme expression by modulating the Nrf2/ARE axis[18; 19]. Nuclear factor-erythroid 2related factor 2 (Nrf2) is an important regulator of antioxidant responsive element (ARE)-activated gene expression. Nrf2 can repair and degrade of damaged macromolecules caused by oxidative stress by upregulating the expression of antioxidant enzyme genes[20]. Studies have shown that the MAPK/Nrf2 pathway improves the antioxidant capacity of eggs by upregulating the mRNA expression of P38MAPK, Nrf2, and HO-1[21]. Moreover, the Nrf2/ARE axis alleviates meat lipid peroxidation by regulating the expression of antioxidant enzymes and phase II enzymes in order to achieve long-term meat storage[22]. However, the potential effect of ASTA on sperm quality, antioxidant capacity, and the MAPK/Nrf2 antioxidant pathway in aging layer roosters was not clear.

Therefore, in the current study, we hypothesized that ASTA can improve semen quality by enhancing antioxidant capacity and activating the MAPK/Nrf2 pathway in aging roosters.

Page 2/19 


\section{Materials And Methods}

\section{Animal care and use}

All experimental protocols were approved by the Animal Care and Use Committee of the Beijing University of Agriculture.

\section{Experimental design}

In the present study, a total of ninety-six 53-week old Jinghong No.1layer breeder roosters with a similar weight and genetic background were supplied by Beijing Huadu Group Co., Ltd. (Beijing, China), and the birds were randomly distributed in four treatments, following a completely randomized design. Each treatment had six replicates, and there were four birds per replicate with one bird per cage $(70 \mathrm{~cm} \times 60 \mathrm{~cm} \times 75 \mathrm{~cm})$. All birds were fed a basal diet for 1 week and then assigned to a corn-soybean meal-based diet containing 0, 25, 50, and $100 \mathrm{mg} / \mathrm{kg}$ ASTA for 6 weeks. Haematococcus pluvialis was purchased from Jingzhou Natural Astaxanthin Inc. (Jingzhou, China), and the ASTA content was 1.54\%. The composition and nutrient levels of the cornsoybean meal-based diet are shown in Table 1. During the experimental period, the birds had 16-h light cycles and were allowed ad libitum access to water and the treatment diets.

Table 1

Composition and nutrient content of basal diets (air dried basis, \%)

\begin{tabular}{|c|c|c|c|}
\hline Ingredients & Content (\%) & Nutrition level & \\
\hline Corn & 69.93 & Metabolizable energy /(MJ·kg $\left.{ }^{-1}\right)$ & 12.02 \\
\hline Soybean meal & 18.60 & Crude protein/\% & 14.00 \\
\hline Wheat bran & 3.80 & Methionine/\% & 0.23 \\
\hline Soybean oil & 1.40 & Lysine/\% & 0.64 \\
\hline Limestone & 2.60 & Calcium/\% & 1.37 \\
\hline Dicalcium phosphate & 1.80 & Total phosphorus/\% & 0.63 \\
\hline Salt & 0.25 & Available phosphorus/\% & 0.44 \\
\hline Choline chloride & \multicolumn{3}{|l|}{0.20} \\
\hline Premix $^{1}$ & \multicolumn{3}{|l|}{1.42} \\
\hline Total & \multicolumn{3}{|l|}{100.00} \\
\hline \multicolumn{4}{|c|}{ 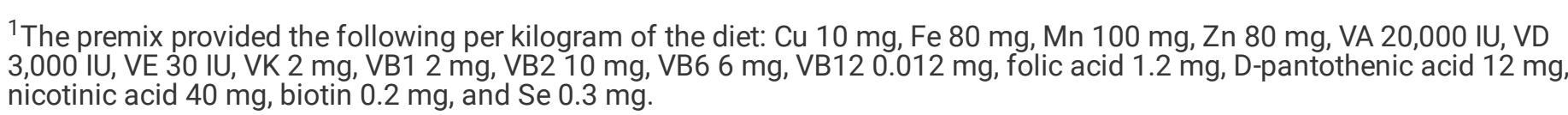 } \\
\hline
\end{tabular}

\section{Semen collection and analysis}

Birds were trained for semen collection every 2 weeks. Semen samples were randomly collected from each bird in each replicate once every two weeks using the abdominal massage method. Next, semen volume was measured with a graduated collecting tube. Semen samples were diluted in a pre-warmed $\left(37^{\circ} \mathrm{C}\right)$ saline solution $(0.9 \%, 1: 49)$, after which samples were assessed for seminal characteristics using CASA system (WLJX-9000 Weili Color Sperm Analysis System; Weili New Century Science \& Tech Dev., Beijing, China), including semen concentration and sperm motility parameters such as sperm motility (\%), average path velocity (VAP, $\mu \mathrm{m} / \mathrm{s})$, straight linear velocity (VSL, $\mu \mathrm{m} / \mathrm{s})$, curvilinear velocity $(\mathrm{VCL}, \mu \mathrm{m} / \mathrm{s})$, amplitude of lateral head displacement $(A L H, \mu m)$, straightness (STR, \%), linearity (LIN, \%), wobble of the curvilinear trajectory (WOB, \%) and beat cross frequency (BCF, $\mathrm{Hz})$.

Sperm viability was evaluated using the eosin-nigrosin stain method. Briefly, a $5 \mu \mathrm{L}$ sperm sample was mixed with $25 \mu \mathrm{L}$ of stain on a pre-warmed slide before the test. Then, the stain was spread with another slide to make a sperm suspension smear. An Olympus BX51 microscope (Olympus Corporation, Tokyo, Japan) was used at a final magnification of 400 to analyze the sperm 
viability. For each sperm sample, five microscopic fields were observed subjectively, and 200 sperms were counted to evaluate viability. Sperm with unstained heads of spermatozoa were considered viable, while sperm displaying partial or complete purple staining were considered nonviable.

\section{Antioxidant enzymes and oxygen free radicals analysis}

After analyzing the semen quality, the semen sample was centrifuged at $4000 \times \mathrm{g}$ for $10 \mathrm{~min}$ at $4{ }^{\circ} \mathrm{C}$, and then the seminal plasma was separated and stored at $-20^{\circ} \mathrm{C}$. At the end of the 6-week feeding trial, one bird from each replicate was randomly selected and sacrificed by cervical dislocation. Immediately after euthanasia, blood samples were collected from the left jugular vein of one bird per replicate. Plasma was separated by centrifugation at $3000 \times g$ for $10 \mathrm{~min}$ and stored at $-20^{\circ} \mathrm{C}$ until analysis. The testis, liver, and kidney were removed immediately and quickly frozen at $-80{ }^{\circ} \mathrm{C}$ for later analysis. These samples were used to analyze the activities of antioxidant enzymes and the ability to scavenge oxygen free radicals. Briefly, antioxidant capacity included the glutathione peroxidase (GSH-Px), superoxide dismutase (SOD), catalase (CAT), and total antioxidant capacity (T$A O C$ ), while oxygen free radical scavenging abilities included hydroxyl radical scavenging ability and superoxide anion scavenging ability. Meanwhile, malondialdehyde (MDA), as the product of lipid metabolism, was analyzed using a spectrophotometric method. These assays were performed using a commercial kit (Nanjing Jiancheng Bio-Engineering Institute, Nanjing, China). The method and principle used to determine the antioxidant indicators with these kits were previouly described elsewhere [23].

\section{Quantitative PCR Analysis}

The mRNA expression levels of $p 38$, extracellular signal-regulated kinase (ERK), c-Jun N-terminal kinase 1 (JNK1), c-Jun Nterminal kinase 2 (JNK2), C-Jun N-terminal kinase 3 (JNK3), Nrf2, Cu-Zn superoxide dismutase (SOD1), Mn superoxide dismutase (SOD2), CAT, glutathione peroxidase 1 (GPX1), and peroxidase 4 (GPX4) were determined via real-time quantitative PCR (RTqPCR) with $\beta$-actin (ACTB) as an internal control in the testis tissues. Total RNA was isolated from $0.1 \mathrm{~g}$ of the testis sample using TRIzol reagent (Invitrogen, Carlsbad, CA, USA) according to the manufacturer's protocol. Then, 1\% agarose gel stained with ethidium bromide was used to confirm the $18 \mathrm{~S}$ and $28 \mathrm{~S}$ bands. Finally, the total RNA concentration was measured using a spectrophotometer at $260 \mathrm{~nm}$. Total RNA was reverse transcribed into cDNA using a Thermo Fisher First cDNA Synthesis Kit (\#K1621; Thermo Fisher Scientific, Waltham, MA, USA). A Step One Plus Real-time PCR system (Applied Biosystems, Foster City, CA, USA) was used for the quantitative PCR analyses. The primers for the selected genes are listed in Table 2. After initial denaturation at $95^{\circ} \mathrm{C}$ for $10 \mathrm{~min}, 40$ cycles of amplification were performed $\left(95^{\circ} \mathrm{C}\right.$ for $10 \mathrm{~s}$ and $58{ }^{\circ} \mathrm{C}$ for $30 \mathrm{~s}$ ), generating melt curves to verify amplification specificity. The relative gene expression levels were calculated using the $2^{-\Delta \Delta C t} \operatorname{method}[24]$, with $A C T B$ as the reference gene. 
Primers used for the real-time quantitative PCR

\begin{tabular}{|c|c|c|c|c|c|}
\hline \multirow{3}{*}{$\begin{array}{l}\text { Genes } \\
\text { ACTB }\end{array}$} & \multirow{2}{*}{$\begin{array}{l}\text { Primer sequence } \\
\left(5^{\prime}-3^{\prime}\right) \\
\text { Forward: GCCAACAGAGAGAAGATGACAC }\end{array}$} & \multicolumn{2}{|c|}{$\begin{array}{l}\text { Fragment } \\
\text { length } \\
\text { (bp) }\end{array}$} & $\begin{array}{l}\text { Annealing } \\
\text { temperature } \\
\left({ }^{\circ} \mathrm{C}\right)\end{array}$ & Accession number \\
\hline & & 118 & 58 & & NM_205518 \\
\hline & Reverse: GTAACACCATCACCAGAGTCCA & & & & \\
\hline \multirow[t]{2}{*}{ SOD1 } & Forward: TTGTCTGATGGAGATCATGGCTTC & 98 & 58 & & NM_205064 \\
\hline & Reverse: TGCTTGCCTTCAGGATTAAAGTGAG & & & & \\
\hline \multirow[t]{2}{*}{ SOD2 } & Forward: CAGATAGCAGCCTGTGCAAATCA & 86 & 58 & & NM_204211.1 \\
\hline & Reverse: GCATGTTCCCATACATCGATTCC & & & & \\
\hline \multirow[t]{2}{*}{$C A T$} & Forward: ACCAAGTACTGCAAGGCGAAAGT & 91 & 58 & & NM_001031215.2 \\
\hline & Reverse: ACCCAGATTCTCCAGCAACAGTG & & & & \\
\hline \multirow[t]{2}{*}{$G P X-1$} & Forward: TTCGAGAAGTTCCTCGTGGG & 79 & 58 & & NM_0012778553.2 \\
\hline & Reverse: CCTGCAGTTTGATGGTCTCG & & & & \\
\hline \multirow[t]{2}{*}{$G P X-4$} & Forward: TCAACCGTGAGGGCCAAGT & 100 & 58 & & NM_001346448.1 \\
\hline & Reverse: CTCGGCACGCAGCTCTAC & & & & \\
\hline \multirow[t]{2}{*}{ Nrf2 } & Forward: ACATGGACAGTTCTCCTGGG & 92 & 58 & & NM_205117.1 \\
\hline & Reverse: CGGCTCCACAGAAGGAAGTA & & & & \\
\hline \multirow[t]{2}{*}{$E R K$} & Forward: AGCAAGCTTTAGCCCATCCA & 108 & 58 & & NM_204150.1 \\
\hline & Reverse: CCTTCGGCAAGTCATCCAAT & & & & \\
\hline \multirow[t]{2}{*}{$J N K 1$} & Forward: GGGTGCATTATGGGCGAAAT & 108 & 58 & & XM_421650.2 \\
\hline & Reverse: TTCTGGGCACGGTGTTCCTA & & & & \\
\hline \multirow[t]{2}{*}{ JNK2 } & Forward: AGCAGCCTCGATGCCTTGAC & 110 & 58 & & AB000807.1 \\
\hline & Reverse: CAAGCAATTCAGGCCCAATG & & & & \\
\hline \multirow[t]{2}{*}{ JNK3 } & Forward: CTGGTGAGTGAGCTGATGGA & 82 & 58 & & NM_001318224.3 \\
\hline & Reverse: ACAGCAGGTAGGACATTCGT & & & & \\
\hline \multirow[t]{2}{*}{ p38 } & Forward: TGTGTTCACCCCTGCCAAGT & 149 & 58 & & AJ719744.1 \\
\hline & Reverse: GCCCCCGAAGAATCTGGTAT & & & & \\
\hline
\end{tabular}

\section{Western blotting analysis}

The protein expression of Nrf2, p38, p-p38, ERK, p-ERK, JNK, and p-JNK was evaluated by western blotting in the testis tissues, and the antibodies are shown in Table 3. Total proteins were extracted from testis tissues using RIPA Buffer (W1001; SinoGene, Beijing, China) according to the manufacturer's instructions. The protein concentration of the extracts was determined using the Bradford method (W1014; SinoGene). Samples containing $30 \mu \mathrm{g}$ of protein and protein markers (SM26616; Thermo Fisher Scientific) were separated by sodium dodecyl sulfate polyacrylamide gel electrophoresis (SDS-PAGE; $4 \%$ stacking gel, $12 \%$ separating gel) at $120 \mathrm{~V}$ for $2 \mathrm{~h}$. Proteins were transferred to polyvinylidene difluoride (PVDF) membranes using a Bio-Rad mini transfer system (Bio-Rad Laboratories, Hercules, CA, USA). The membranes were blocked with Fast Protein-free Block Buffer (\#W1028; SinoGene) for $5 \mathrm{~min}$ and then incubated with primary antibody (1:1000 dilution) overnight at $4{ }^{\circ} \mathrm{C}$. After rinsing four 
times with TBST for 10 min per rinse, HRP-conjugated secondary antibody (SA00001-2, ptg) was applied to the membranes at a dilution of 1:3000 for $1 \mathrm{~h}$. Then, after rinsing three times with Tris-buffered saline with $0.1 \%$ Tween ${ }^{\circledR} 20$ Detergent (TBST) for 10 min per rinse, immunological signals were detected using a chemiluminescent (ECL) kit (29050; Engreen) and exposed to X-ray films in the dark. Protein bands were quantified by densitometric analysis using Image $\mathrm{J}$ analysis software (National Institutes of Health, Bethesda, MD, USA).

Table 3

Antibodies used for the western blot analysis.

\begin{tabular}{|llll|}
\hline Antibodies & Cat NO. & Source & Dilution \\
\hline p38 & 9212 & Cell Signaling Technology, Danvers, MA, USA & $1: 1000$ \\
\hline p-p38 & 4511 & Cell Signaling Technology, Danvers, MA, USA & $1: 1000$ \\
\hline ERK & 4695 & Cell Signaling Technology, Danvers, MA, USA & $1: 1000$ \\
\hline p-ERK & 9101 & Cell Signaling Technology, Danvers, MA, USA & $1: 1000$ \\
\hline JNK & 9252 & Cell Signaling Technology, Danvers, MA, USA & $1: 1000$ \\
\hline p-JNK & 4668 & Cell Signaling Technology, Danvers, MA, USA & $1: 1000$ \\
\hline Nrf2 & ab31163 & Abcam, Cambridge, UK & $1: 5000$ \\
\hline B-Actin & AC028 & Abclonal, Woburn, MA, USA & $1: 3000$ \\
\hline
\end{tabular}

\section{Statistical analysis}

Statistical analysis was performed using SPSS 22.0 (IBM Corp., Armonk, NY, USA). Data related to the effect of dietary ASTA levels on semen quality, antioxidant capacity, gene and protein expression were analyzed by one-way analysis of variance with orthogonal linear and quadratic contrasts. Duncan's multiple comparison test was used to examine statistical differences among the treatments. Statistical significance was defined as $P<0.05$.

\section{Results And Discussion}

\section{Semen quality}

Semen quality is considered to be a crucial factor in roosters' fertility because the fertility rate is positively correlated with sperm motility, sperm concentration, and sperm motility parameters in roosters[25]. Few reports have described the effects of ASTA on semen quality in aging roosters. We evaluated the effects of dietary ASTA on semen quality in aging roosters (Table 4). Briefly, there were no differences in semen quality between the control group and the ASTA groups at week 0 . The semen volume was significantly higher in the $25 \mathrm{mg} / \mathrm{kg}$ ASTA group than that in the other groups at week $6(P<0.05)$. Meanwhile, with an increase in dietary ASTA, sperm viability and sperm concentration significantly increased compared to those in the control group $(P<0.05)$. In particular, the sperm concentration was linearly and quadratically affected $(P<0.05)$ by the dietary ASTA levels. In addition, the sperm motility parameters of aging layer roosters in the $50 \mathrm{mg} / \mathrm{kg}$ ASTA group were significantly linearly increased relative to those in the control group $(P<0.05)$. Moreover, sperm motility increased from $64.395-76.234 \%$ in the $0-100 \mathrm{mg} / \mathrm{kg}$ ASTA-treated group $(P<0.05)$. It has been previously demonstrated that sperm viability, total motility, and sperm kinematic parameters increase after ASTA treatment in mice[26]. A recent study also showed similar results: ASTA can improve post-thawed rooster sperm motility and kinetic parameters, including total motility, progressive motility, VAP, VSL, and LIN. However, there was no significant difference in LIN, STR, ALH, and BCF in the ASTA treatment groups compared to those in the control[27]. Interestingly, the opposite result was observed in the current study that the motility parameters including STR, LIN, WOB, VSL, VAP, BCF, and ALH in the ASTA groups were significantly higher than those in the control group $(P<0.05)$. The discrepant results may be partly related to the level of ASTA addition, the duration of supplementation, and the test subjects. Taken together, these findings indicated that dietary ASTA supplementation significantly increased the semen quality during the test period (0-6 weeks). However, the possible mechanisms by which dietary ASTA affects semen quality are not well understood, but may be related to antioxidant defense system. 
Table 4

Effect of dietary natural astaxanthin (ASTA) supplementation on the semen quality of aging layer breeder roosters

\begin{tabular}{|c|c|c|c|c|c|c|c|c|c|}
\hline \multirow[t]{2}{*}{ Items } & \multirow{2}{*}{$\begin{array}{l}\text { Time } \\
\text { (week) }\end{array}$} & \multicolumn{4}{|c|}{ ASTA levels / (mg/kg) } & \multirow[t]{2}{*}{ SEM } & \multicolumn{3}{|c|}{$P$-value } \\
\hline & & 0 & 25 & 50 & 100 & & ANOVA & Linear & Quadratic \\
\hline \multirow[t]{4}{*}{ Semen volume (mL) } & 0 & 0.245 & 0.258 & 0.255 & 0.242 & 0.005 & 0.606 & 0.769 & 0.199 \\
\hline & 2 & $0.252^{b}$ & $0.309^{a}$ & $0.274^{b}$ & $0.274^{b}$ & 0.006 & $<0.01$ & 0.429 & $<0.01$ \\
\hline & 4 & $0.242^{b}$ & $0.305^{a}$ & $0.289^{a}$ & $0.286^{a}$ & 0.006 & $<0.01$ & $<0.01$ & $<0.01$ \\
\hline & 6 & $0.252^{b}$ & $0.336^{a}$ & $0.317^{a}$ & $0.31^{a}$ & 0.054 & $<0.01$ & $<0.01$ & $<0.01$ \\
\hline \multirow[t]{4}{*}{ Sperm viability (\%) } & 0 & 83.83 & 81.33 & 82.17 & 82.83 & 0.42 & 0.185 & 0.549 & 0.06 \\
\hline & 2 & $85.33^{b}$ & $89.17^{a}$ & $90.83^{a}$ & $90.83^{a}$ & 0.65 & $<0.01$ & $<0.01$ & 0.063 \\
\hline & 4 & $83.17^{c}$ & $88.67^{b}$ & $90.17^{a b}$ & $91.50^{\mathrm{a}}$ & 0.75 & $<0.01$ & $<0.01$ & 0.011 \\
\hline & 6 & $85.67^{c}$ & $91.33^{\mathrm{ab}}$ & $91.00^{b}$ & $94.67^{a}$ & 0.87 & $<0.01$ & $<0.01$ & 0.40 \\
\hline \multirow{4}{*}{$\begin{array}{l}\text { Sperm } \\
\text { concentration }\left(10^{8} / \mathrm{mL}\right)\end{array}$} & 0 & 11.357 & 11.278 & 11.303 & 11.366 & 3.148 & 0.742 & 0.862 & 0.291 \\
\hline & 2 & $11.369^{b}$ & $11.489^{b}$ & $11.844^{\mathrm{a}}$ & $11.956^{\mathrm{a}}$ & 5.427 & $<0.01$ & $<0.01$ & 0.931 \\
\hline & 4 & $11.374^{c}$ & $12.036^{\mathrm{b}}$ & $12.154^{\mathrm{b}}$ & $12.421^{\mathrm{a}}$ & 8.489 & $<0.01$ & $<0.01$ & $<0.01$ \\
\hline & 6 & $11.33^{c}$ & $12.569^{b}$ & $12.623^{\mathrm{b}}$ & $12.965^{a}$ & 13.523 & $<0.01$ & $<0.01$ & $<0.01$ \\
\hline \multirow[t]{4}{*}{ STR (\%) } & 0 & 79.764 & 79.725 & 79.51 & 79.323 & 0.783 & 0.997 & 0.839 & 0.965 \\
\hline & 2 & $78.082^{c}$ & $84.222^{b}$ & $87.144^{a}$ & $84.772^{\mathrm{ab}}$ & 0.815 & $<0.01$ & $<0.01$ & $<0.01$ \\
\hline & 4 & $79.236^{c}$ & $84.269^{b}$ & $87.377^{a}$ & $86.635^{a}$ & 0.747 & $<0.01$ & $<0.01$ & $<0.01$ \\
\hline & 6 & $76.534^{b}$ & $85.283^{a}$ & $86.743^{a}$ & $87.413^{a}$ & 1.013 & $<0.01$ & $<0.01$ & $<0.01$ \\
\hline \multirow[t]{4}{*}{ LIN (\%) } & 0 & 44.781 & 44.568 & 45.51 & 43.034 & 0.429 & 0.224 & 0.259 & 0.186 \\
\hline & 2 & $45.156^{c}$ & $53.476^{\mathrm{b}}$ & $55.586^{a}$ & $55.955^{a}$ & 0.99 & $<0.01$ & $<0.01$ & $<0.01$ \\
\hline & 4 & $48.07^{c}$ & $54.102^{b}$ & $57.377^{a}$ & $57.468^{\mathrm{a}}$ & 0.857 & $<0.01$ & $<0.01$ & $<0.01$ \\
\hline & 6 & $45.467^{c}$ & $61.142^{\mathrm{a}}$ & $61.078^{a}$ & $58.087^{\mathrm{b}}$ & 1.43 & $<0.01$ & $<0.01$ & $<0.01$ \\
\hline \multirow[t]{4}{*}{ WOB (\%) } & 0 & 52.731 & 53.159 & 53.065 & 52.091 & 0.408 & 0.811 & 0.604 & 0.422 \\
\hline & 2 & $53.903^{c}$ & $58.392^{b}$ & $59.617^{\mathrm{b}}$ & $63.089^{a}$ & 0.787 & $<0.01$ & $<0.01$ & 0.542 \\
\hline & 4 & $54.267^{c}$ & $61.104^{\mathrm{ab}}$ & $59.132^{b}$ & $63.069^{a}$ & 0.774 & $<0.01$ & $<0.01$ & 0.08 \\
\hline & 6 & $52.961^{c}$ & $69.569^{a}$ & $71.067^{\mathrm{a}}$ & $64.15^{b}$ & 1.62 & $<0.01$ & $<0.01$ & $<0.01$ \\
\hline \multirow[t]{3}{*}{$\operatorname{VCL}(\mu \mathrm{m} / \mathrm{s})$} & 0 & 63.226 & 61.61 & 62.294 & 62.57 & 0.396 & 0.572 & 0.726 & 0.256 \\
\hline & 2 & $62.403^{c}$ & $67.73^{b}$ & $76.292^{a}$ & $69.393^{b}$ & 1.099 & $<0.01$ & $<0.01$ & $<0.01$ \\
\hline & 4 & $60.631^{d}$ & $70.735^{c}$ & $80.973^{b}$ & $85.911^{a}$ & 2.142 & $<0.01$ & $<0.01$ & 0.096 \\
\hline
\end{tabular}

a-d Means within a row with no common superscripts differ significantly $(P<0.05)$. Data represent the mean of six replicates. Abbreviations: SEM, standard error of the mean; ANOVA, analysis of variance; VAP, average path velocity; VSL, straight linear velocity; VCL, curvilinear velocity; ALH, amplitude of lateral head displacement; STR, straightness; LIN, linearity; WOB, wobble of the curvilinear trajectory; BCF, beat cross frequency. 


\begin{tabular}{|c|c|c|c|c|c|c|c|c|c|}
\hline & 6 & $59.894^{c}$ & $73.602^{b}$ & $80.763^{a}$ & $83.072^{a}$ & 2.009 & $<0.01$ & $<0.01$ & $<0.01$ \\
\hline \multirow[t]{4}{*}{ VSL $(\mu \mathrm{m} / \mathrm{s})$} & 0 & 29.595 & 29.752 & 29.381 & 28.56 & 0.447 & 0.81 & 0.416 & 0.607 \\
\hline & 2 & $31.673^{c}$ & $32.719^{b c}$ & $36.371^{\mathrm{b}}$ & $46.35^{a}$ & 1.354 & $<0.01$ & $<0.01$ & $<0.01$ \\
\hline & 4 & $30.82^{c}$ & $38.916^{b}$ & $41.511^{\mathrm{b}}$ & $45.976^{a}$ & 1.268 & $<0.01$ & $<0.01$ & 0.132 \\
\hline & 6 & $30.024^{b}$ & $40.53^{a}$ & $37.129^{a}$ & $41.164^{a}$ & 1.198 & $<0.01$ & $<0.01$ & 0.072 \\
\hline \multirow[t]{4}{*}{$\operatorname{VAP}(\mu \mathrm{m} / \mathrm{s})$} & 0 & 32.264 & 31.996 & 31.056 & 32.379 & 0.406 & 0.834 & 0.939 & 0.458 \\
\hline & 2 & $31.192^{d}$ & $35.268^{c}$ & $41.78^{b}$ & $47.127^{a}$ & 1.332 & $<0.01$ & $<0.01$ & 0.468 \\
\hline & 4 & $32.999^{c}$ & $44.309^{b}$ & $45.593^{b}$ & $53.379^{a}$ & 1.629 & $<0.01$ & $<0.01$ & 0.148 \\
\hline & 6 & $32.093^{c}$ & $46.592^{a}$ & $47.366^{a}$ & $41.523^{b}$ & 1.439 & $<0.01$ & $<0.01$ & $<0.01$ \\
\hline \multirow[t]{4}{*}{$\mathrm{BCF}(\mathrm{Hz})$} & 0 & 3.568 & 3.53 & 3.672 & 3.545 & 0.032 & 0.423 & 0.802 & 0.498 \\
\hline & 2 & $3.534^{c}$ & $3.81^{b}$ & $3.97^{a}$ & $4.047^{a}$ & 0.045 & $<0.01$ & $<0.01$ & 0.024 \\
\hline & 4 & $3.528^{c}$ & $4.068^{b}$ & $4.60^{a}$ & $4.141^{b}$ & 0.084 & $<0.01$ & $<0.01$ & $<0.01$ \\
\hline & 6 & $3.59^{c}$ & $3.889^{b}$ & $4.44^{\mathrm{a}}$ & $4.387^{a}$ & 0.079 & $<0.01$ & $<0.01$ & $<0.01$ \\
\hline \multirow[t]{4}{*}{ Sperm motility (\%) } & 0 & 63.072 & 61.520 & 63.000 & 61.948 & 0.502 & 0.649 & 0.687 & 0.811 \\
\hline & 2 & $62.554^{b}$ & $65.200^{\mathrm{ab}}$ & $67.951^{a}$ & $66.508^{a}$ & 0.615 & $<0.01$ & $<0.01$ & 0.049 \\
\hline & 4 & $62.000^{c}$ & $68.833^{b}$ & $69.779^{a b}$ & $71.667^{\mathrm{a}}$ & 0.851 & $<0.01$ & $<0.01$ & $<0.01$ \\
\hline & 6 & $64.395^{\mathrm{b}}$ & $65.768^{\mathrm{b}}$ & $73.414^{\mathrm{a}}$ & $76.234^{\mathrm{a}}$ & 1.229 & $<0.01$ & $<0.01$ & 0.611 \\
\hline \multirow[t]{4}{*}{$\operatorname{ALH}(\mu \mathrm{m})$} & 0 & 2.195 & 2.282 & 2.180 & 2.203 & 0.145 & 0.645 & 0.776 & 0.602 \\
\hline & 2 & $2.122^{\mathrm{c}}$ & $2.307^{b c}$ & $2.462^{b}$ & $2.962^{\mathrm{a}}$ & 0.076 & $<0.01$ & $<0.01$ & 0.082 \\
\hline & 4 & $2.346^{\mathrm{b}}$ & $3.099^{a}$ & $3.045^{a}$ & $3.295^{\mathrm{a}}$ & 0.087 & $<0.01$ & $<0.01$ & 0.015 \\
\hline & 6 & $2.105^{c}$ & $2.998^{b}$ & $3.018^{b}$ & $3.361^{\mathrm{a}}$ & 0.107 & $<0.01$ & 0.011 & $<0.01$ \\
\hline \multicolumn{10}{|c|}{$\begin{array}{l}\text { a-d Means within a row with no common superscripts differ significantly }(P<0.05) \text {. Data represent the mean of six replicates } \\
\text { Abbreviations: SEM, standard error of the mean; ANOVA, analysis of variance; VAP, average path velocity; VSL, straight linear } \\
\text { velocity; VCL, curvilinear velocity; ALH, amplitude of lateral head displacement; STR, straightness; LIN, linearity; WOB, wobble } \\
\text { of the curvilinear trajectory; BCF, beat cross frequency. }\end{array}$} \\
\hline
\end{tabular}

\section{Antioxidant enzyme activity and free radical scavenging ability}

In aging roosters, a decreased in the antioxidant defense system, makes rooster spermatozoa vulnerable to lipid peroxidation[28]. Other studies have reported that senescence occurs due to the damage caused by free radicals and reactive oxygen species (ROS) to DNA, lipids, and proteins[29; 30]. Sophisticated enzymatic (SOD, CAT and GSH-Px) and non-enzymatic (vitamins A, C, E, and carotenoids) antioxidants constitute an antioxidant defense system that can regulate overall ROS levels to maintain physiological homeostasis[31]. ASTA, as a natural carotenoid antioxidant, can be transferred to the right place in the tissues and exert antioxidant effects at an appropriate concentration[32]. Previous studies haves demonstrated that ASTA has a higher antioxidant activity relative to a-carotene, lycopene, lutein, and $\beta$-carotene[33], and the capacity of scavenging singlet oxygen is about 550 times more than that of vitamin E[34]. Thus, in this study, the effects of dietary ASTA addition on antioxidant enzyme activity and free radical scavenging ability in the plasma, seminal plasma, testes, liver, and kidney of aging layer breeder roosters are shown in Figures 1 to 5 . Briefly, the $25 \mathrm{mg} / \mathrm{kg}$ ASTA level linearly and quadratically increased the GSH-Px activity in the plasma, testis, and liver of aging layer roosters compared with that in the control group $(P<0.05)$. The activities of SOD and CAT also increased gradually with increasing dietary ASTA supplementation from 50 to $100 \mathrm{mg} / \mathrm{kg}(P<0.05)$. Furthermore, MDA 
concentrations decreased linearly with increasing dietary ASTA levels $(P<0.05)$ in birds. With an increase in dietary ASTA, the levels of T-AOC increased linearly $(P<0.05)$. This observation is consistent with a previous report that in general, the activities of SOD, CAT, and GSH-Px in the brain and liver of rats increased dramatically at treatment with ASTA, respectively[36; 35]. In addition, we found that dietary ASTA supplementation linearly and quadratically increased the abilities of scavenging hydroxyl radicals and superoxide anions compared with those in the control group, which was consistent with a previous study[37]. In particular, the abilities of scavenging hydroxyl radical and superoxide anion of aging roosters were significantly increased in the $50 \mathrm{mg} / \mathrm{kg}$ ASTA group $(P<0.05)$.

\section{Relationship between semen quality and antioxidant enzyme activity}

When the age of male poultry is over 45 weeks, semen volume, sperm concentration, viability, and forward motility decrease, whereas lipid peroxidation in seminal plasma increases[38]. Therefore, in the present study, we aimed to improve the quality of semen by improving the antioxidant capacity of aging roosters using dietary ASTA. Moreover, it has been demonstrated that antioxidant capacity plays an important role in maintaining sperm viability because it can protect against lipid peroxidation in semen[39]. MDA is an important indicator of lipid peroxidation. A previous study showed that sperm motility was negatively correlated with MDA content in spermatozoa[40]. In the current study, the MDA content in the semen plasma, plasma, and tissues showed a dose-dependent decrease with changes in dietary ASTA. Similar findings were obtained in rats in which ASTA group showed a significant increase in SOD and CAT activities, as well as a significant decrease in MDA levels and repaired the oxidative stress-induced fertility disorder[41]. Therefore, the improvement of semen quality in aging roosters may be related to two factors. First, antioxidant enzyme activity remarkably improved, and MDA concentration decreased linearly with increasing dietary ASTA concentration, which plays an important role in the prevention of oxidative damage in the sperm plasma membrane. Second, dietary ASTA may improve the ability to neutralize singlet oxygen and scavenge radicals to inhibit lipid peroxidation, protect sperm from free radicals, and improve semen quality.

\section{Gene expression of SOD1, SOD2, CAT, GPX1, and GPX4}

The activity of an antioxidant enzyme is closely related to its gene expression[42]. The mRNA levels of SOD1, SOD2, CAT, GPX1, and GPX4 were determined to evaluate the effects of ASTA on the gene expression of antioxidant enzymes in aging rooster testis tissues (Figure 6). In the present study, the SOD1 and SOD2 mRNA levels in the $50 \mathrm{mg} / \mathrm{kg}$ ASTA groups were higher than those in the other groups $(P<0.05)$. SOD1 is mainly soluble in the cytoplasm and SOD2 is mitochondrial, and ASTA has both lipophilic and hydrophilic properties, which can directly produce effects in or outside the cell membrane[43]. This may be the reason why the gene expression of SOD1 and SOD2 was improved by adding dietary ASTA. Additionally, in the dietary ASTA supplementation group, the GPX1 and GPX4 mRNA levels were significantly increased relative to those in the control group $(P<0.05)$. However, there were no differences in the GPX1 mRNA levels among the 50 and $100 \mathrm{mg} / \mathrm{kg}$ ASTA-treated groups. Furthermore, an increase in dietary ASTA supplementation from 0 to $100 \mathrm{mg} / \mathrm{kg}$ linearly increased the mRNA expression of $C A T(P<0.05)$. Similarly, in a previous study, dietary ASTA increased the oxidative damage repair potential of mice and upregulated the mRNA levels of GPX1, SOD1, SOD2, and CAT in the liver and kidney[44]. Therefore, it would be interesting to further study the mechanism of how dietary ASTA affects semen quality in aging roosters by improving the antioxidant defense system.

\section{Gene and protein expression in the MAPK/Nrf2 pathway}

Nrf2 plays an important role in the antioxidant response, and it has been reported that the MAPK kinase pathway regulates the Nrf2 action. When the nuclear transcription factor Nrf2 is phosphorylated and activated by MAPKs (such as ERK and p38), it can be translocated to the nucleus, leading to the upregulation of antioxidant enzyme expression[22]. Therefore, in order to clarify whether ASTA could activate this pathway, the gene and protein expression in the MAPK/Nrf2 pathway in testis tissues were measured in the four groups, and the results are presented in Figures 7 and 8 . In this study, significant differences in the mRNA levels of Nrf2, ERK, P38, and JNK were observed among all of the ASTA-added groups in the testis (Figure 7). Briefly, when the concentration of dietary ASTA reached $50 \mathrm{mg} / \mathrm{kg}$, the mRNA levels of $N r f 2, E R K, P 38$, and JNK2 were significantly higher than those in the control group $(P<0.05)$ and reached the maximum. A significant increase in JNK1 mRNA expression was observed

in the $100 \mathrm{mg} / \mathrm{kg}$ ASTA group $(P<0.05)$. Moreover, an increase in dietary ASTA from 0 to $100 \mathrm{mg} / \mathrm{kg}$ linearly enhanced the mRNA expression of JNK3 $(P<0.05)$. This finding indicated that dietary ASTA increased the gene expression of $N r f 2$ and upregulated 
the expression of upstream signals (MAPKs). Western blot analysis revealed that dietary ASTA effectively elevated $(P<0.05)$ the ratio of the phosphorylated MAPKs (p38, ERK, and JNK) to total MAPKs (p38, ERK, and JNK) compared to that in the control (Figure 8). Briefly, the results showed that ASTA treatment remarkably upregulated the p-p38, p-ERK, and p-JNK expression in the testis $(P<0.05)$. In particular, the p-p38, p-JNK, and Nrf2 protein levels in the $25 \mathrm{mg} / \mathrm{kg}$ ASTA group were higher than those in the other groups. In addition, when the concentration of dietary ASTA reached $50 \mathrm{mg} / \mathrm{kg}, \mathrm{p}$-ERK protein levels were significantly higher than those in the control group $(P<0.05)$ and reached the maximum. However, Niu et al., 2018 [45] observed an opposite result in that dietary ASTA supplementation did not affect the p-38 and p-JNK levels but significantly increased the p-ERK levels. Differences in test subjects, and test conditions may explain these discrepant results.

\section{Relationships among the MAPK/Nrf2 pathway and antioxidant enzymes and semen quality}

Aging is a complex phenomenon that is associated with an irreversible and progressive decline in body function due to biochemical and morphological changes[46]. In the process of aging, there are obvious characteristics such as increase in oxidative stress, a decline in cell function, and defects in tissues and organs[47]. In aging male animals, morphological changes in the testis include a reduction in the volume and quantity of germ cells, which leads to a decrease in sperm quality and fertilization[48]. Therefore, in this study, we explored whether dietary ASTA can improve the semen quality of aging roosters by activating the MAPK/Nrf2 pathway to enhance the service life of aging roosters. The MAPK signaling pathway is involved in many cellular functions, such as inflammation, cell proliferation, cell differentiation, and cell death[18]. Meanwhile, the MAPK signaling pathway can regulate the expression of antioxidant enzymes in various cell types and adapt to various extracellular stresses through the Nrf2/ARE axis[49]. Nrf2 is a major factor that regulates antioxidant responses, and dissociates from Keap1 upon the oxidative response and translocates to the nucleus, wherein it is phosphorylated at serine 40 by the MAPK pathway, leading to the upregulation of the gene expression of antioxidant enzymes[50]. There is a high proportion of polyunsaturated fatty acids in the plasma membrane of bird sperm, and with an increase in age, the antioxidant capacity of sperm decreases. Once the plasma membrane of bird sperm is exposed to ROS, it is prone to lipid peroxidation [51]. Thus, the decrease in total antioxidant capacity of semen is considered to be one of the reasons for the decline of fertilization ability in aging roosters[52]. In the current study, our results revealed that dietary ASTA elevated the MAPK phosphorylation (p38, ERK, JNK), and the mRNA and protein expression of Nrf2 were remarkably enhanced by adding $50 \mathrm{mg} / \mathrm{kg}$ ASTA in the diets, which was in agreement with a previous study[53]. In addition, the SOD1, SOD2, CAT, GPX1, and GPX4 mRNA levels were higher in the dietary ASTA group than those in the control group, which led to the enhancement of antioxidant capacity and semen quality in aging roosters. These results indicate that dietary ASTA can activate the MAPK/Nrf2 pathway, upregulate Nrf2 transcription and translation, and promote the expression of downstream antioxidant enzyme genes, enhancing the antioxidant capacity and improving the semen quality in aging roosters.

\section{Conclusions}

In summary, the results of this study confirmed our hypothesis that dietary ASTA supplementation improves the semen quality of aging roosters, as reflected by the upregulation of the antioxidant system (Fig. 9). Therefore, these findings suggest that dietary ASTA could attenuate age-related sub-fertility in aging layer breeder roosters. However, the possible mechanisms by which ASTA ameliorates sperm quality are not well understood. Therefore, it is necessary to evaluate the effect of dietary ASTA on semen quality by the MAPK/Nrf2 signaling pathway in vitro.

\section{Abbreviations}

ACTB, $\beta$-actin; ALH, amplitude of lateral head displacement; ARE, antioxidant responsive element; ASTA, natural astaxanthin; BCF, beat cross frequency; CAT, catalase; GPX1, glutathione peroxidase 1; GPX4, peroxidase 4; GSH-Px, glutathione peroxidase; ERK, extracellular signal-regulated kinase; JNK1, c-Jun N-terminal kinase 1; JNK2, c-Jun N-terminal kinase 2; JNK3, c-Jun N-terminal kinase 3; LIN, linearity; MAPK, mitogen-activated protein kinase; MDA, malondialdehyde; Nrf2, Nuclear factor-erythroid 2-related factor 2; SOD, superoxide dismutase; SOD1, Cu-Zn superoxide dismutase; SOD2, Mn superoxide dismutase STR, straightness; TAOC, total antioxidant capacity; VAP, average path velocity; VCL, curvilinear velocity; VSL, straight linear velocity; WOB, wobble of the curvilinear trajectory. 


\section{Declarations}

\section{Acknowledgments}

The authors thank the Animal Breeding and Assisted Reproduction Lab of Beijing University of Agriculture for technical support, and thank Editage (www.editage.cn) for English language editing.

\section{Funding}

This study was supported by Modern Agricultural Industry Technology System-Peking Poultry Innovation Team (BAIC04-2021), National Key R\&D Program of China (2016YFD0700201).

\section{Availability of data and materials}

The data for the current study are available from the corresponding author upon reasonable request.

\section{Authors' contributions}

SG, XLQ, NH, and FL conceived and designed the experiments. SG performed animal experiments, analyzed the data and wrote the manuscript. XLQ, YG, and HMN assisted with data analysis and paper writing. YC and LW supervised and provided continuous guidance for the animal experiment. XHS, XGW, KX, and LFX supervised and provided continuous guidance for the Molecular experiment. All authors read and approved the final manuscript.

\section{Ethics approval}

All experimental protocols were approved by the Animal Care and Use Committee of the Beijing University of Agriculture.

\section{Consent for publication}

Not applicable.

\section{Competing interests}

The authors have no conflicts of interest to declare.

\section{References}

1. Sun Y, Xue F, Li Y, Fu L, Bai H, Ma H, et al. Differences in semen quality, testicular histomorphology, fertility, reproductive hormone levels, and expression of candidate genes according to sperm motility in beijing-you chickens. Poult Sci. 2019;98(9):4182-9. doi:https://doi.org/10.3382/ps/pez208.

2. Lagares MA, Ecco R, Martins N, Lara L, Rocha J, Vilela D, et al. Detecting reproductive system abnormalities of broiler breeder roosters at different ages. Reprod Domest Anim. 2017;52(1):67-75. doi:10.1111/rda.12804.

3. Ansari M, Zhandi M, Kohram H, Zaghari M, Sadeghi M, Gholami M, et al. D-aspartate amends reproductive performance of aged roosters by changing gene expression and testicular histology. Reproduction Fertility Development. 2018;30(7):1038. doi:10.1071/RD17072.

4. Ansari M, Zhandi M, Kohram H, Zaghari M, Sadeghi M, Sharafi M. Improvement of post-thawed sperm quality and fertility of arian rooster by oral administration of d-aspartic acid. Theriogenology. 2017;92:69-74.

5. Qi X, Shang M, Chen C, Chen Y, Hua J, Sheng X, et al. Dietary supplementation with linseed oil improves semen quality, reproductive hormone, gene and protein expression related to testosterone synthesis in aging layer breeder roosters. Theriogenology. 2019;131:9-15. doi:10.1016/j.theriogenology.2019.03.016.

6. Mangiagalli MG, Martino PA, Smajlovic T, Guidobono Cavalchini L, Marelli SP. Effect of lycopene on semen quality, fertility and native immunity of broiler breeder. Br Poult Sci. 2010;51(1):152-7. 
7. Yan W, Kanno C, Oshima E, Kuzuma Y, Kim SW, Bai H, et al. Enhancement of sperm motility and viability by turmeric byproduct dietary supplementation in roosters. Animal Reproduction Science. 2017;185:195-204. doi:10.1016/j.anireprosci.2017.08.021.

8. Liu Z, Zeng X, Cheng J, Liu D, Aadil RM. The efficiency and comparison of novel techniques for cell wall disruption in astaxanthin extraction fromhaematococcus pluvialis. Int J Food Sci Technol. 2018;53(9):2212-9. doi:10.1111/ijfs.13810.

9. Ushakumari UN, Ravi R. Isolation of astaxanthin from marine yeast and study of its. International Current Pharmaceutical Journal. 2013;3(2):67-9.

10. Ambati R, Phang S, Ravi S, Aswathanarayana R. Astaxanthin: sources, extraction, stability, biological activities and its commercial applications-a review. Mar Drugs. 2014;12(1):128-52. doi:10.3390/md12010128.

11. Sarada R, Tripathi U, Ravishankar GA. Influence of stress on astaxanthin production in haematococcus pluvialis grown under different culture conditions. Process Biochem. 2002;37(6):623-7.

12. Samorì C, Pezzolesi L, Galletti P, Semeraro M, Tagliavini E. Extraction and milking of astaxanthin from haematococcus pluvialis cultures. Green Chem. 2019;21(13):3621-8. doi:10.1039/C9GC01273G.

13. Capelli B, Bagchi D, Cysewski GR. Synthetic astaxanthin is significantly inferior to algal-based astaxanthin as an antioxidant and may not be suitable as a human nutraceutical supplement. Nutrafoods. 2013;12(4):145-52. doi:10.1007/s13749-0130051-5.

14. Singh KN, Patil S, Barkate H. Protective effects of astaxanthin on skin: recent scientific evidence, possible mechanisms, and potential indications. Journal of Cosmetic Dermatology. 2019;19(1):22-7. doi:10.1111/jocd.13019.

15. Dose J, Matsugo S, Yokokawa H, Koshida Y, Okazaki S, Seidel U, et al. Free radical scavenging and cellular antioxidant properties of astaxanthin. Int J Mol Sci. 2016;17(1):103. doi:10.3390/ijms17010103.

16. Iskender H, Yenice G, Dokumacioglu E, Hayirli A, Sevim C, Dokumacioglu A, et al. Astaxanthin alleviates renal damage of rats on high fructose diet through modulating $\mathrm{nfkb} / \mathrm{sirt1}$ pathway and mitigating oxidative stress. Arch Physiol Biochem. 2020;126(1):89-93. doi:10.1080/13813455.2018.1493609.

17. Li Z, Handong W. Multiple mechanisms of anti-cancer effects exerted by astaxanthin. Mar Drugs. 2015;13(7):4310-30.

18. Truong AD, Hong Y, Lee J, Lee K, Lillehoj HS, Hong YH. Analysis of mapk signaling pathway genes in the intestinal mucosal layer of necrotic eenteritis-afflicted two inbred chicken lines. Korean Journal of Poultry Science. 2017;44(3):199-209. doi:10.5536/KJPS.2017.44.3.199.

19. Xu L, Zhang H, Yue H, Wu S, Yang H, Qi G, et al. Low-current \& high-frequency electrical stunning increased oxidative stress, lipid peroxidation, and gene transcription of the mitogen-activated protein kinase/nuclear factor-erythroid 2-related factor 2/antioxidant responsive element (mapk/nrf2/are) signaling pathway in breast muscle of broilers. Food Chem. 2018;242:491-6. doi:10.1016/j.foodchem.2017.09.079.

20. Hayes JD, Dinkova-Kostova AT. The nrf2 regulatory network provides an interface between redox and intermediary metabolism. Trends Biochem Sci. 2014;39(4):199-218. doi:10.1016/j.tibs.2014.02.002.

21. Wang J, Jia R, Celi P, Ding X, Bai S, Zeng Q, et al. Green tea polyphenol epigallocatechin-3-gallate improves the antioxidant capacity of eggs. Food Funct. 2020;11(1):534-43. doi:10.1039/C9FO02157D.

22. Xu L, Zhang H, Yue H, Wu S, Yang H, Wang Z, et al. Gas stunning with co2 affected meat color, lipid peroxidation, oxidative stress, and gene expression of mitogen-activated protein kinases, glutathione s-transferases, and cu/zn-superoxide dismutase in the skeletal muscles of broilers. Journal of Animal Science Biotechnology. 2018;9(1). doi:10.1186/s40104-0180252-2.

23. Qi X, Shugeng W, Haijun Z, Hongyuan Y, Shaohui X, Feng J, et al. Effects of dietary conjugated linoleic acids on lipid metabolism and antioxidant capacity in laying hens. Archives of Animal Nutrition. 2011;65(5):354-65.

24. Livak KJ, Schmittgen TD. Analysis of relative gene expression data using real-time quantitative pcr and the $2-\delta \delta c t$ method. Methods. 2001;(25): 402-8.

25. Tesfay HH, Sun Y, Li Y, Shi L, Fan J, Wang P, et al. Comparative studies of semen quality traits and sperm kinematic parameters in relation to fertility rate between 2 genetic groups of breed lines. Poult Sci. 2020;99(11):6139-46. doi:https://doi.org/10.1016/j.psj.2020.06.088.

Page 12/19 
26. Wang L, Zhuang L. Astaxanthin ameliorates the lipopolysaccharides-induced subfertility in mouse via nrf2/ho- 1 antioxidant pathway. Dose-Response. 2019;17(3):500660723. doi:10.1177/1559325819878537.

27. Najafi D, Taheri RA, Najafi A, Shamsollahi M, Alvarez-Rodriguez M. Effect of astaxanthin nanoparticles in protecting the postthawing quality of rooster sperm challenged by cadmium administration. Poult Sci. 2020;99(3):1678-86. doi:https://doi.org/10.1016/j.psj.2019.12.006.

28. Kelso KA, Cerolini S, Noble RC, Sparks NHC, Speake BK. Lipid and antioxidant changes in semen of broiler fowl from 25 to 60 weeks of age. Journal of Reproduction Fertility. 1996;106(2):201-6.

29. Stadtman ER. Protein oxidation and aging. Science. 1992;257(5074):1220-4.

30. Valko M, Leibfritz D, Moncol J, Cronin MTD, Mazur M, Telser J. Free radicals and antioxidants in normal physiological functions and human disease. The International Journal of Biochemistry Cell Biology. 2007;39(1):44-84. doi:10.1016/j.biocel.2006.07.001.

31. Jiménez-Escrig A. Polyphenol and carotenoid protection in biological systems through the modulation of antioxidant enzymes. Curr Enzym Inhib. 2006;2(3):231-48.

32. Sajad Fakhri FALD, Jorjani M. Astaxanthin: a mechanistic review on its biological activities and health benefits. Pharmacological Research. 2018.

33. Naguib AYM. Antioxidant activities of astaxanthin and related carotenoids. Journal of agricultural food. 2000;48(4):1150-4.

34. Shimidzu N. MGAW. Carotenoids as singlet oxygen quenchers in marine organisms. Fish Sci. 1996;62(1):134-7.

35. Xu J, Rong S, Gao H, Chen C, Yang W, Deng Q, et al. A combination of flaxseed oil and astaxanthin improves hepatic lipid accumulation and reduces oxidative stress in high fat-diet fed rats. Nutrients. 2017;9(3):271. doi:10.3390/nu9030271.

36. Nai Y, Liu H, Bi X, Gao H, Ren C. Protective effect of astaxanthin on acute cerebral infarction in rats. Human Experimental Toxicology. 2017;37(9):929-36. doi:10.1177/0960327117745693.

37. Zhao X, Zhang X, Liu H, Zhu H, Zhu Y. Enzyme-assisted extraction of astaxanthin from haematococcus pluvialis and its stability and antioxidant activity. Food Sci Biotechnol. 2019;28(6):1637-47. doi:10.1007/s10068-019-00608-6.

38. Fouad AM, El-Senousey HK, Ruan D, Xia W, Chen W, Wang S, et al. Nutritional modulation of fertility in male poultry. Poult Sci. 2020;99(11):5637-46. doi:10.1016/j.psj.2020.06.083.

39. Eslami M, Ghaniei A, Mirzaei Rad H. Effect of the rooster semen enrichment with oleic acid on the quality of semen during chilled storage. Poult Sci. 2016;95(6):1418-24.

40. Suleiman SA, ALI ME, ZAKI ZMS, EL-MALIK EMA, NASR MA. Lipid peroxidation and human sperm motility: protective role of vitamin e. J Androl. 1996;17(5):530-7.

41. Heidari Khoei H, Fakhri S, Parvardeh S, Shams Mofarahe Z, Baninameh Z, Vardiani M. Astaxanthin prevents the methotrexate-induced reproductive toxicity by targeting oxidative stress in male mice. Toxin Reviews. 2019;38(3):248-54. doi:10.1080/15569543.2018.1452263.

42. Qi X, Wang J, Yue H, Wu S, Zhang Y, Ni H, et al. Trans10, cis12-conjugated linoleic acid exhibits a stronger antioxidant capacity than cis9, trans11-conjugated linoleic acid in primary cultures of laying hen hepatocytes. Poult Sci.

2018;97(12):4415-24. doi:10.3382/ps/pey297.

43. Gao S, Li R, Heng N, Chen Y, Wang L, Li Z, et al. Effects of dietary supplementation of natural astaxanthin from haematococcus pluvialis on antioxidant capacity, lipid metabolism, and accumulation in the egg yolk of laying hens. Poult Sci. 2020;99(11):5874-82. doi:10.1016/j.psj.2020.08.029.

44. Ni Y, Wu T, Yang L, Xu Y, Ota T, Fu Z. Protective effects of astaxanthin on a combination of d-galactose and jet lag-induced aging model in mice. Endocr J. 2018;65(5):569-78. doi:10.1507/endocrj.EJ17-0500.

45. Niu T, Xuan R, Jiang L, Wu W, Zhen Z, Song Y, et al. Astaxanthin induces the nrf2/ho-1 antioxidant pathway in human umbilical vein endothelial cells by generating trace amounts of ros. J Agric Food Chem. 2018;66(6):1551-9. doi:10.1021/acs.jafc.7b05493.

46. Sayed RKA, Mokhtar DM, Fernández-Ortiz M, Fernández-Martínez J, Aranda-Martínez P, Escames G, et al. Lack of retinoid acid receptor-related orphan receptor alpha accelerates and melatonin supplementation prevents testicular aging. Aging (Albany NY). 2020;12(13):12648-68. doi:10.18632/aging.103654. 
47. Tae Kawahara TKYU, Goh Kimura MNTH, Kurasaki TSTS. Elucidation of the mechanism of changes in the antioxidant function with the aging in the liver of the senescence-accelerated. Exp Gerontol. 2018;106(6):46-53.

48. Beattie MC, Adekola L, Papadopoulos V, Chen H, Zirkin BR. Leydig cell aging and hypogonadism. Exp Gerontol. 2015;68:8791. doi:10.1016/j.exger.2015.02.014.

49. Hen-Hsi, Yang, Andrew D, Sharrocks A, et al. Map kinase signalling cascades and transcriptional regulation. Gene. 2013;513(1):1-13.

50. Yang YC, Lii CK, Lin AH, Yeh YW, Yao HT, Li CC, et al. Induction of glutathione synthesis and heme oxygenase 1 by the flavonoids butein and phloretin is mediated through the erk/nrf2 pathway and protects against oxidative stress. Free Radical Biol Med. 2011;51(11):2073-81.

51. Khan RU. Antioxidants and poultry semen quality. Worlds Poultry ence Journal. 2011;67(2):297-308.

52. Borghei-Rad SM, Zeinoaldini S, Zhandi M, Moravej H, Ansari M. Feeding rosemary leaves powder ameliorates rooster agerelated subfertility. Theriogenology. 2017;101:35-43.

53. Wu Q, Zhang X, Wang H, Zhang X, Yu Q, Li W, et al. Astaxanthin activates nuclear factor erythroid-related factor 2 and the antioxidant responsive element (nrf2-are) pathway in the brain after subarachnoid hemorrhage in rats and attenuates early brain injury. Mar Drugs. 2014;12(12):6125-41. doi:10.3390/md12126125.

\section{Figures}

A

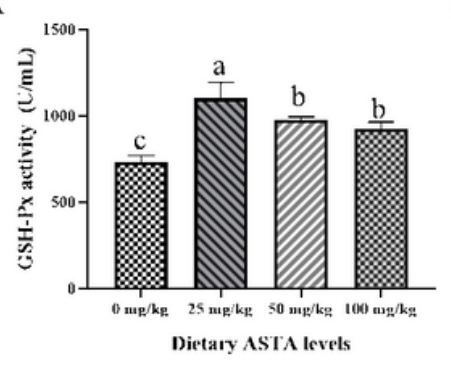

E

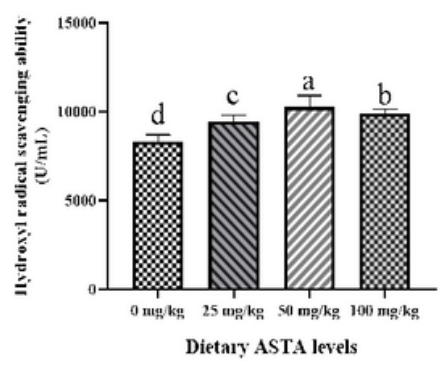

B

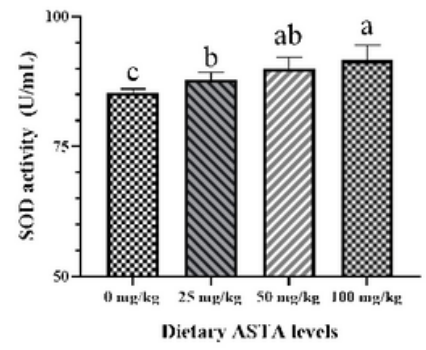

F

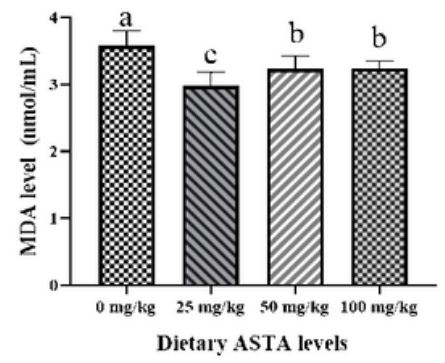

C

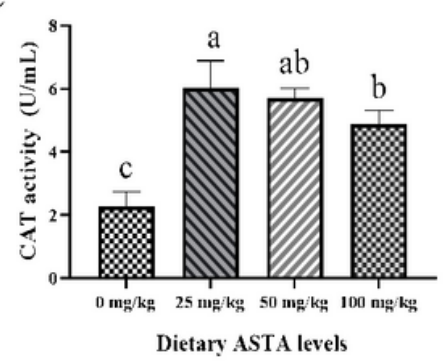

G

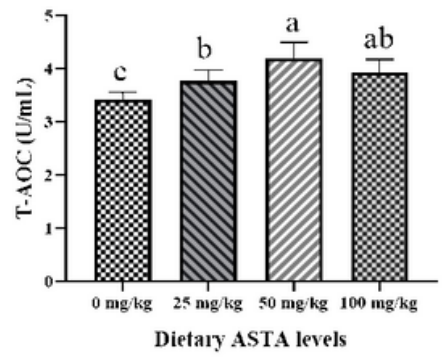

D

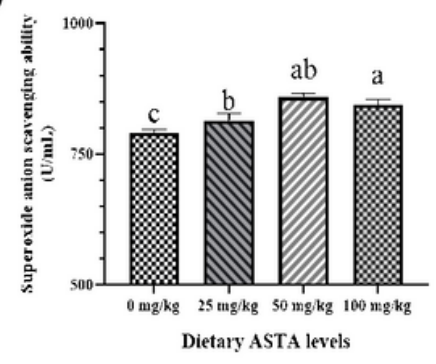

Dietary ASTA levels

\section{Figure 1}

Effect of dietary natural astaxanthin (ASTA) supplementation on the antioxidant enzyme activity and free radicals in the plasma of aging layer breeder roosters. (A-C) Glutathione peroxidase (GSH-Px), superoxide dismutase (SOD), and catalase (CAT) activity in the plasma. (D-E) Scavenging free radical abilities in the plasma. (F) Malondialdehyde (MDA) level in the plasma. (G) Total antioxidant capacity (T-AOC) in the plasma. The data represent the mean \pm standard deviation; $n=6$ in each group. a- $d$ Means within a row with no common superscripts differ significantly $(P<0.05)$. 
A

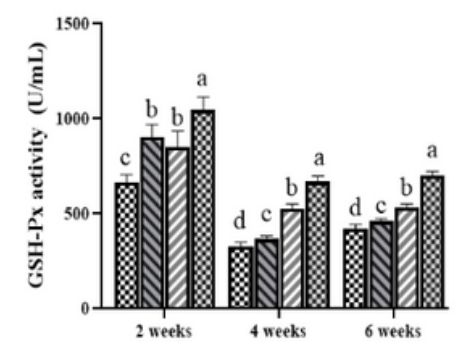

B

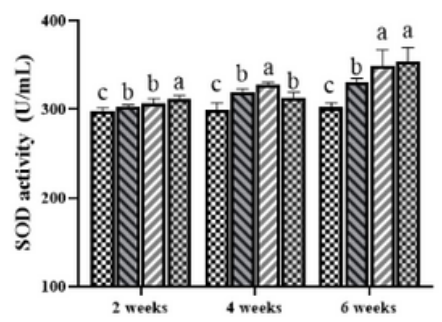

$\mathrm{F}$

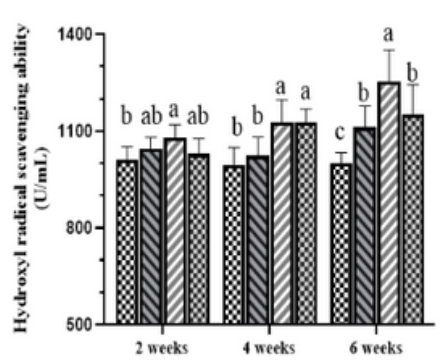

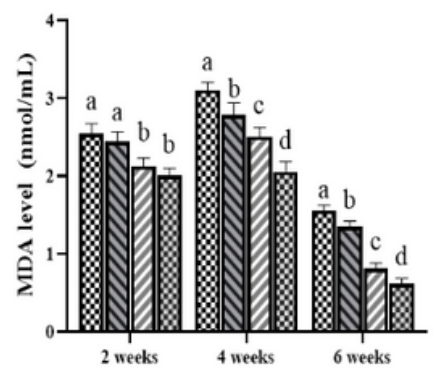

$\mathrm{C}$

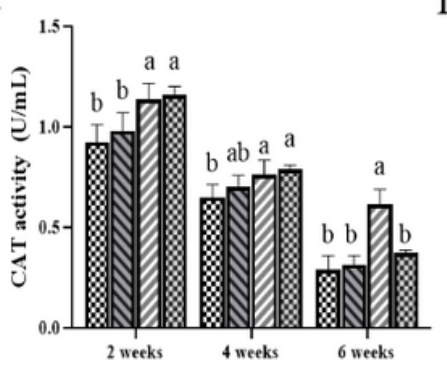

G

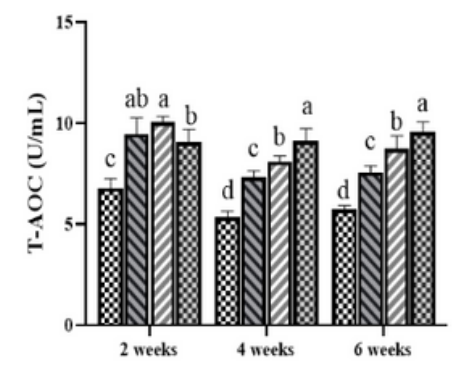

$\mathrm{D}$
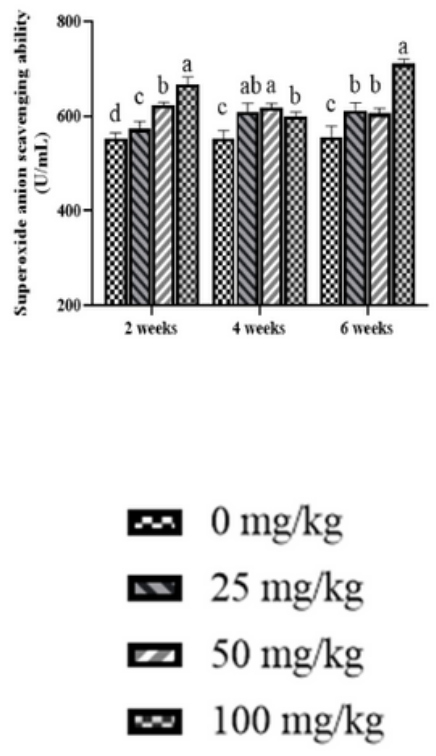

Figure 2

Effect of dietary natural astaxanthin (ASTA) supplementation on antioxidant enzyme activity and free radicals in the seminal plasma of aging layer breeder roosters. (A-C) Glutathione peroxidase (GSH-Px), superoxide dismutase (SOD), and catalase (CAT) activity in the seminal plasma. (D-E) Scavenging free radical abilities in the seminal plasma. (F) Malondialdehyde (MDA) level in the seminal plasma. (G) Total antioxidant capacity (T-AOC) in the seminal plasma. The data represent the mean \pm standard deviation; $n=6$ in each group. a-d Means within a row with no common superscripts differ significantly $(P<0.05)$

A

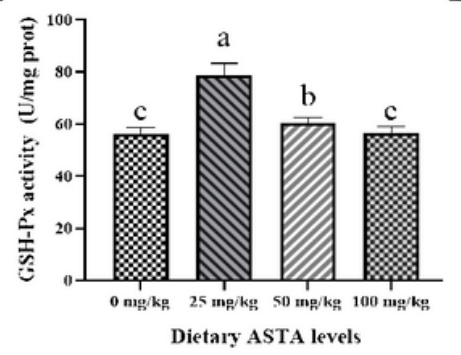

E

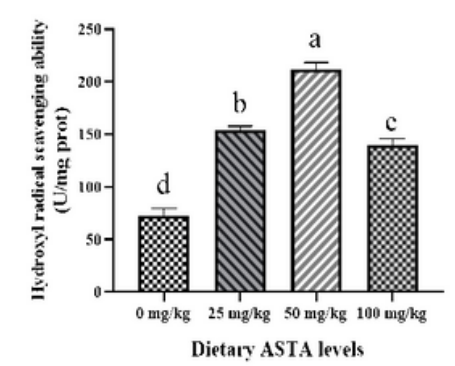

B

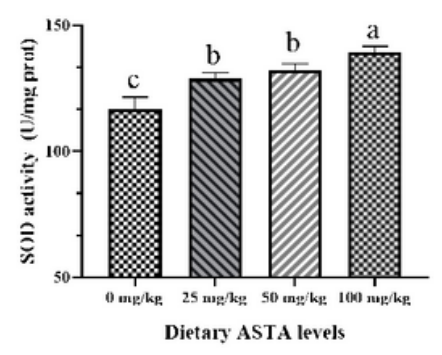

F

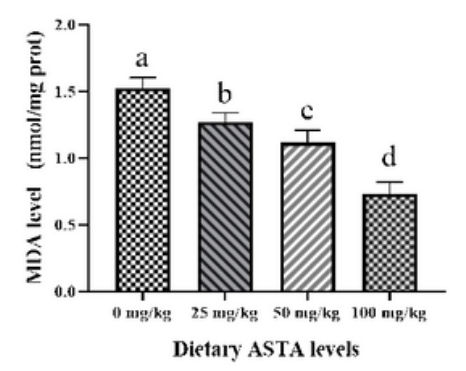

$\mathrm{C}$

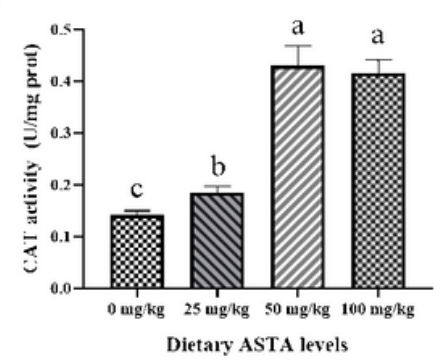

G

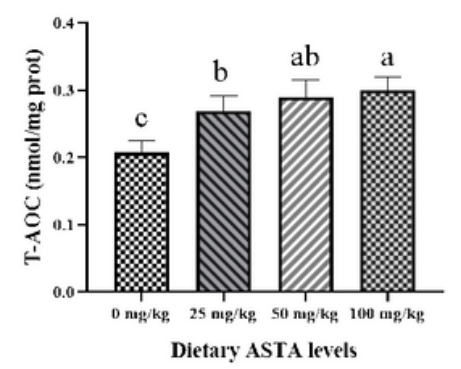

$\mathrm{D}$

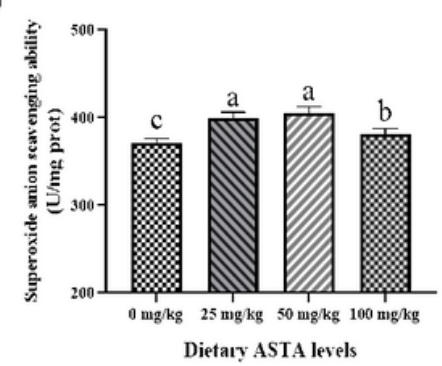

Dietary ASTA levels

Figure 3

Effect of dietary natural astaxanthin (ASTA) supplementation on the antioxidant enzyme activity and free radicals in the testis of aging layer breeder roosters. (A-C) Glutathione peroxidase (GSH-Px), superoxide dismutase (SOD), and catalase (CAT) activity in the testis. (D-E) Scavenging free radical abilities in the testis. (F) Malondialdehyde (MDA) level in the testis. (G) Total antioxidant 
capacity (T-AOC) in the testis. The data represent the mean \pm standard deviation; $n=6$ in each group. $a-d$ Means within a row with no common superscripts differ significantly $(P<0.05)$.

A

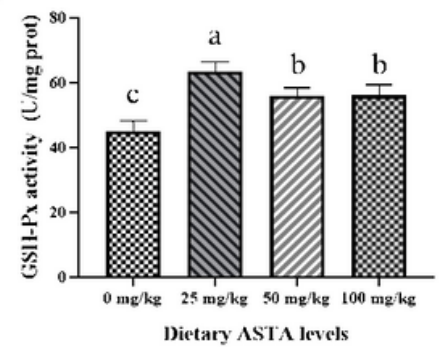

$\mathrm{E}$

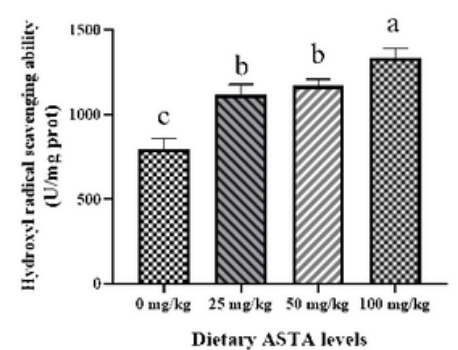

B

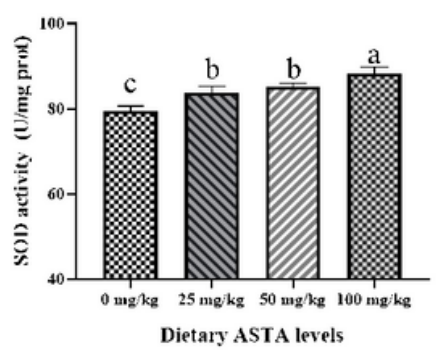

$\mathrm{F}$

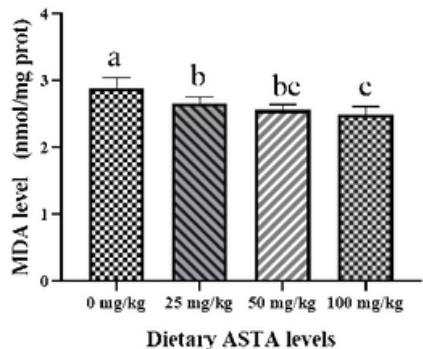

$\mathrm{C}$

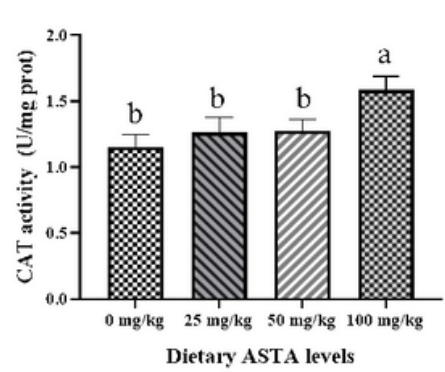

G

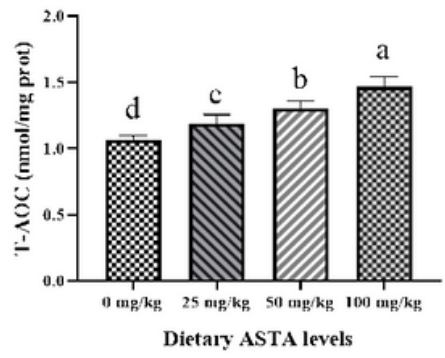

Figure 4

Effect of dietary natural astaxanthin (ASTA) supplementation on the antioxidant enzyme activity and free radicals in the liver of aging layer breeder roosters. (A-C) Glutathione peroxidase (GSH-Px), superoxide dismutase (SOD), and catalase (CAT) activity in the liver. (D-E) Scavenging free radical abilities in the liver. (F) Malondialdehyde (MDA) level in the liver. (G) Total antioxidant capacity (T-AOC) in the liver. The data represent the mean \pm standard deviation; $n=6$ in each group. $a-d$ Means within a row with no common superscripts differ significantly $(P<0.05)$.

A

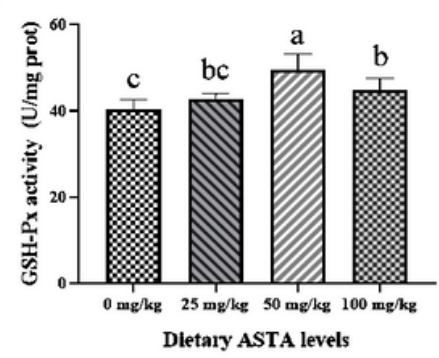

$\mathrm{E}$

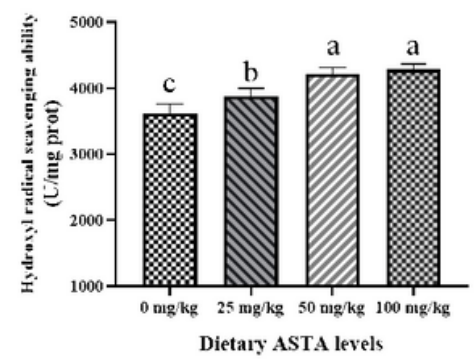

B

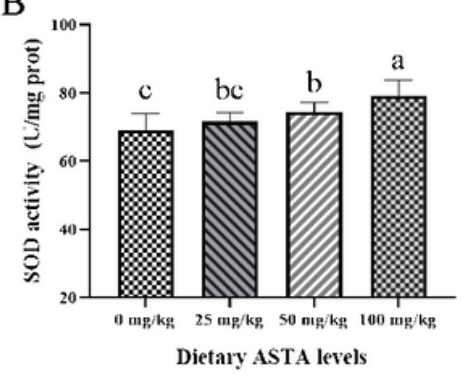

$\mathrm{F}$

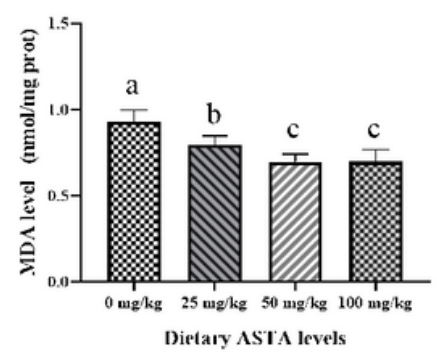

$\mathrm{C}$

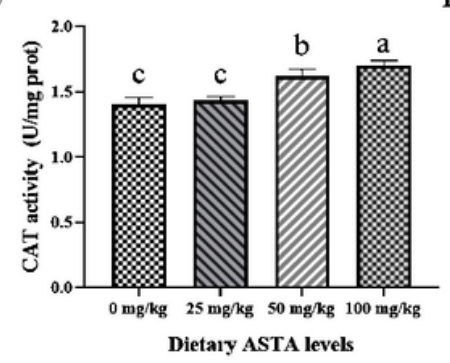

G

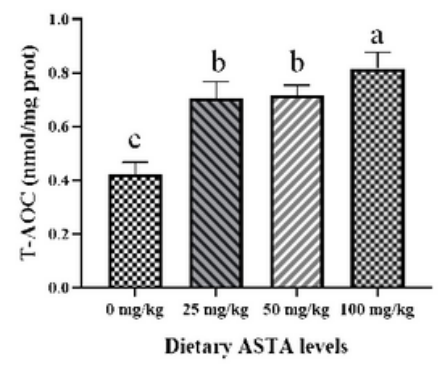

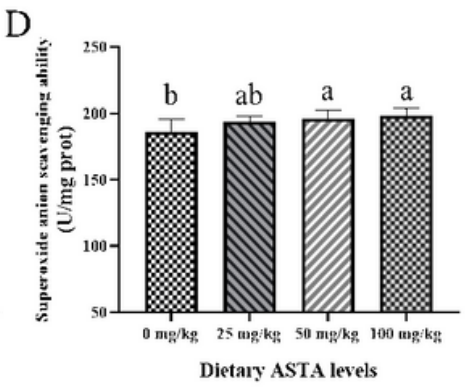

Dietary ASTA levels

$\mathrm{D}$

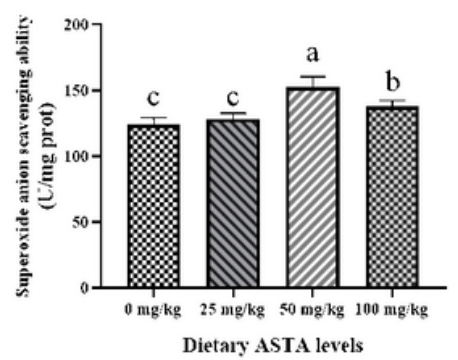

Dietary ASTA levels

\section{Figure 5}

Effect of dietary natural astaxanthin (ASTA) supplementation on the antioxidant enzyme activity and free radicals in kidney of aging layer breeder roosters. (A-C) Glutathione peroxidase (GSH-Px), superoxide dismutase (SOD), and catalase (CAT) activity in the kidney. (D-E) Scavenging free radicals abilities in the kidney. (F) Malondialdehyde (MDA) level in the kidney. (G)Total 
antioxidant capacity (T-AOC) in the kidney. The data represent the mean \pm standard deviation; $n=6$ in each group. a-c Means within a row with no common superscripts differ significantly $(P<0.05)$.
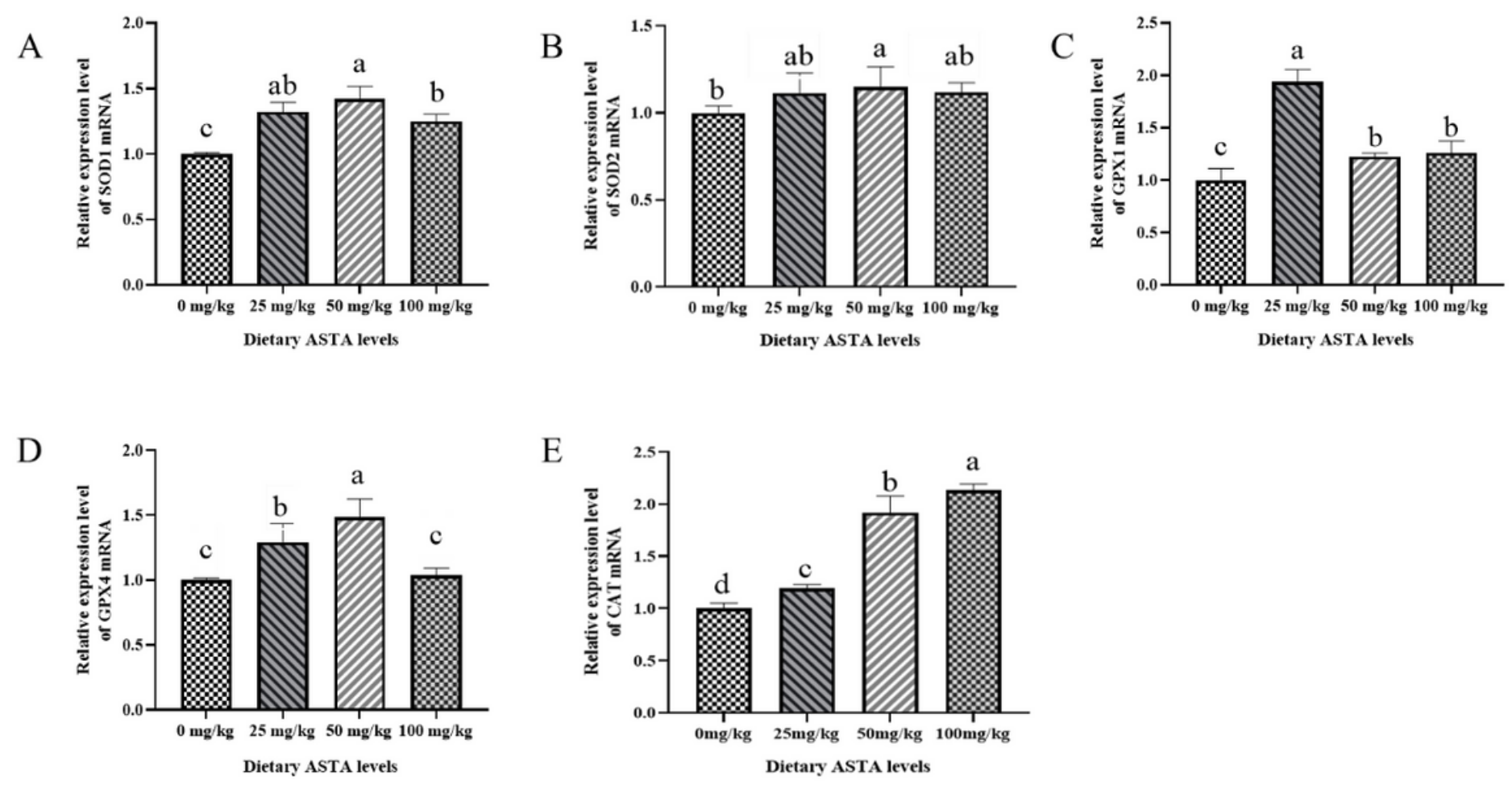

Figure 6

Effects of dietary natural astaxanthin (ASTA) supplementation on the mRNA expression of antioxidant enzymes, including Cu-Zn superoxide dismutase (SOD1) (A), Mn superoxide dismutase (SOD2) (B), glutathione peroxidase 1 (GPX1) (C), peroxidase 4 (GPX4) (D), and catalase (CAT) (E), relative to that of $\beta$-actin (ACTB). The values are expressed as the means \pm standard deviation of six birds per treatment. a-d Means within a row with no common superscripts differ significantly $(P<0.05)$.

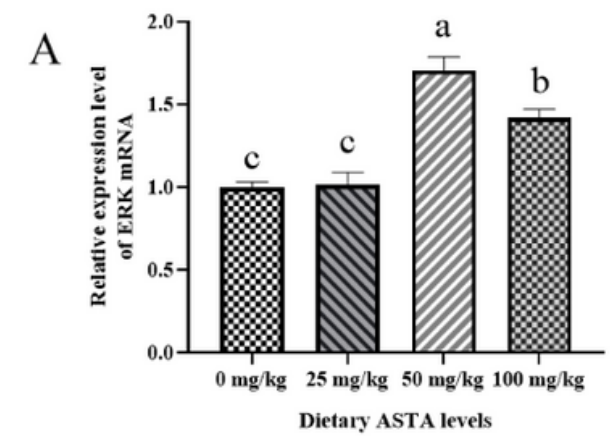

D

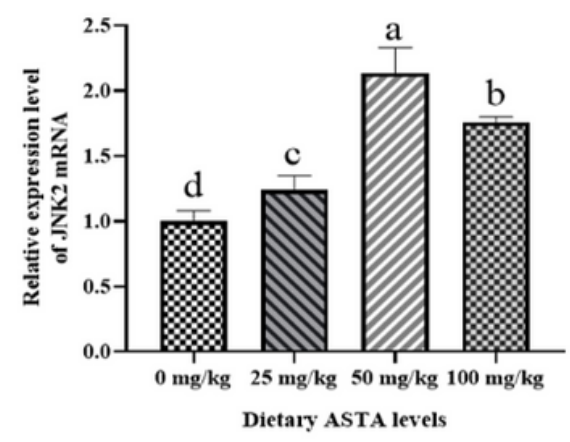

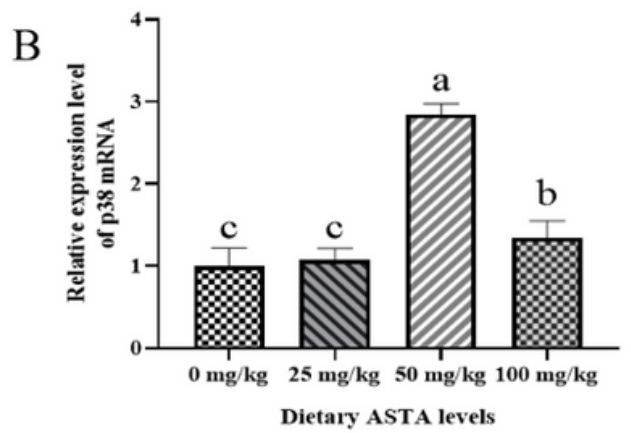

$\mathrm{E}$

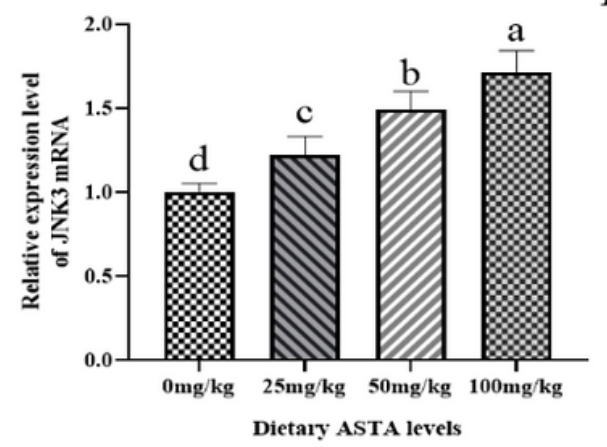

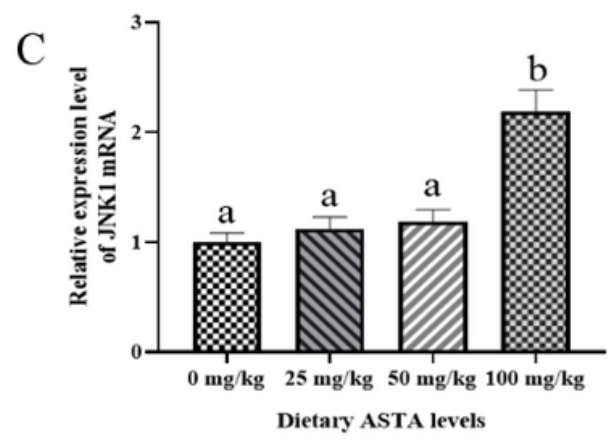

$\mathrm{F}$

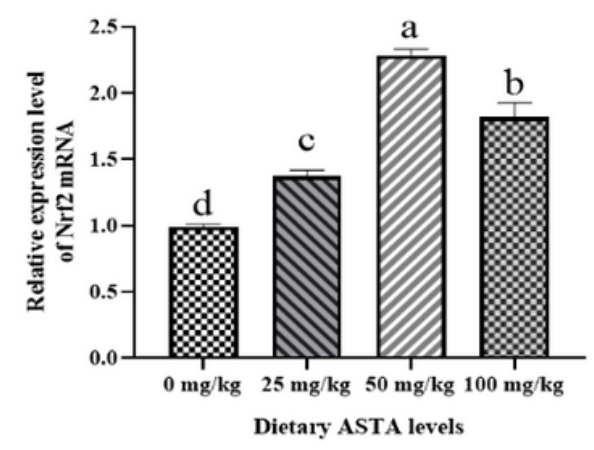

Figure 7 
Effects of dietary natural astaxanthin (ASTA) supplementation on the mRNA expression of the mitogen-activated protein kinase/nuclear factor-erythroid 2-related factor 2 (MAPK/Nrf2) signaling pathway, including extracellular signal-regulated kinase (ERK) (A), p38 (B), c-Jun N-terminal kinase 1 (JNK1) (C), c-Jun N-terminal kinase 2 (JNK2) (D), c-Jun N-terminal kinase 3 (JNK3) $(E)$, and Nrf2 (F) relative to that of $\beta$-actin (ACTB). The values are expressed as the means \pm standard deviation of six birds per treatment. a-d Means within a row with no common superscripts differ significantly $(P<0.05)$.

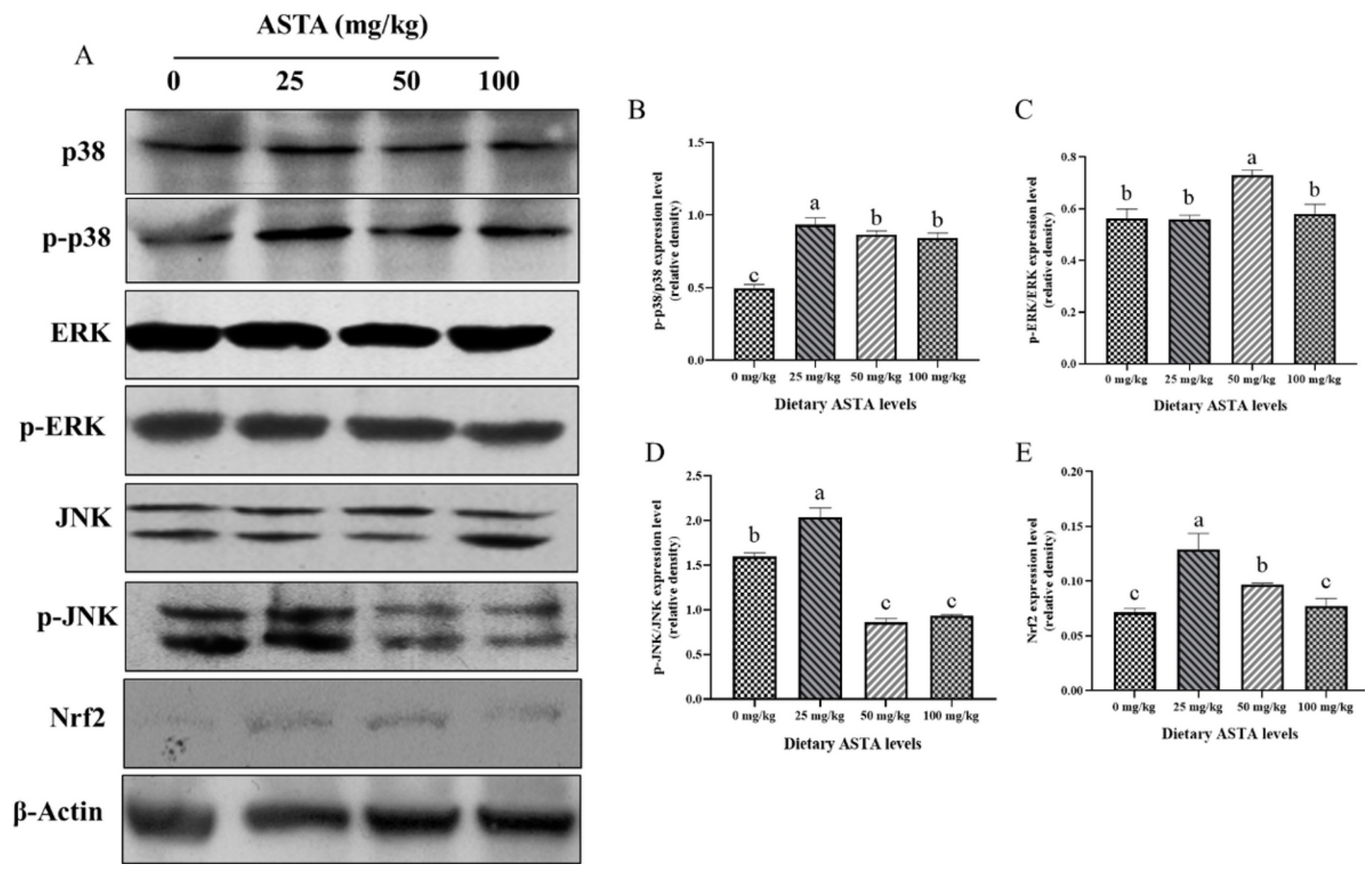

\section{Figure 8}

Effects of dietary natural astaxanthin (ASTA) on the expression of proteins related to the mitogen-activated protein kinase/nuclear factor-erythroid 2-related factor 2 (MAPK/Nrf2) pathway in the testis tissues of aging layer breeder roosters. The experimental groups included the control group $(0 \mathrm{mg} / \mathrm{kg})$ and ASTA groups $(25-100 \mathrm{mg} / \mathrm{kg})$. The results are expressed as the means \pm standard deviation $(n=3)$. a-c Means within a row with no common superscripts differ significantly $(P<0.05)$. 


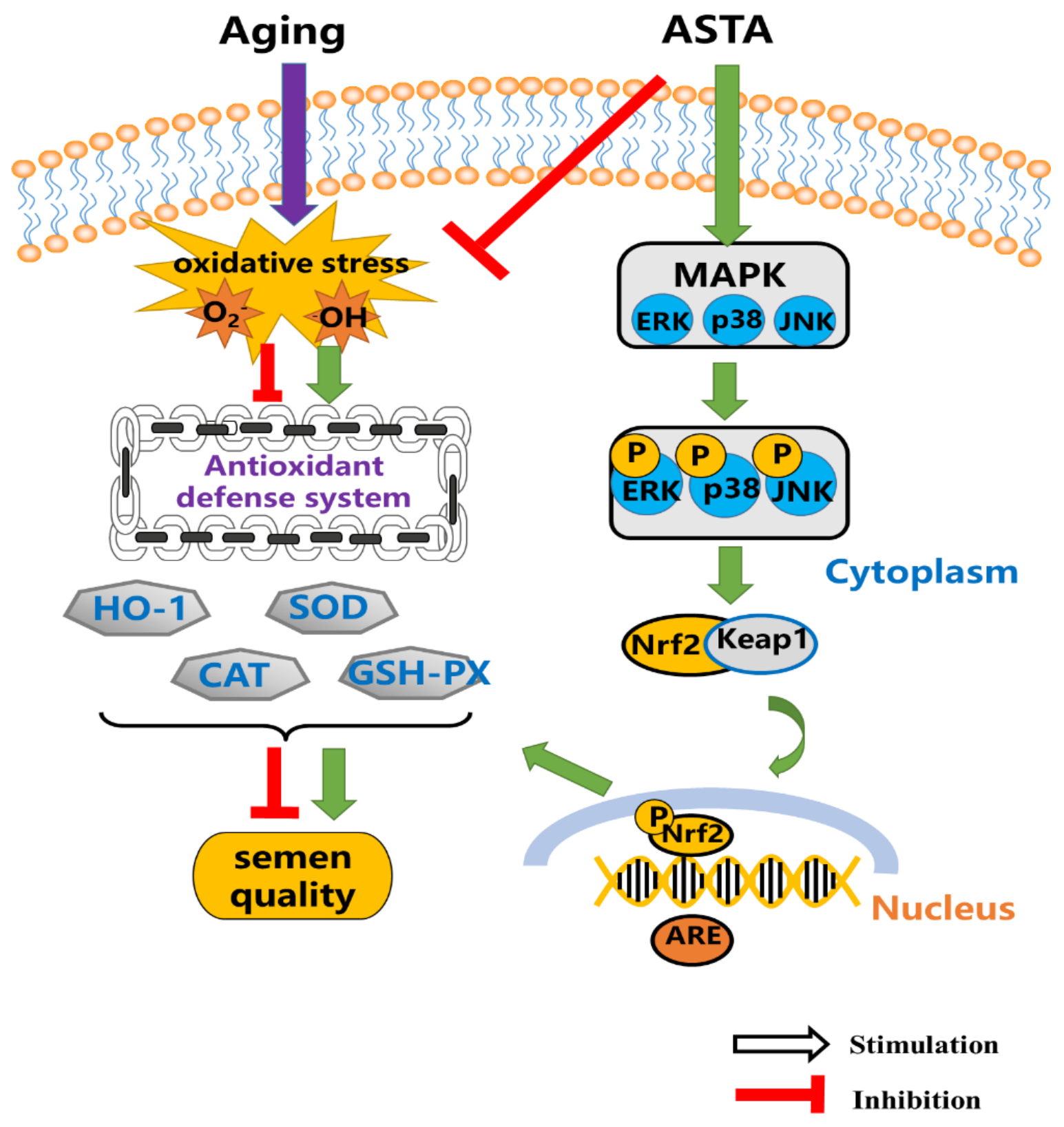

Figure 9

Schematic diagram summarizing the mechanisms by which natural astaxanthin (ASTA) promotes the antioxidant defense system in aging roosters. The antioxidant defense system is down-regulated in the natural aging process in roosters. ASTA attenuated the oxidative stress in the testis via the activation of the mitogen-activated protein kinase/nuclear factor-erythroid 2related factor 2 (MAPK/Nrf2) pathway to attenuate the age-related sub-fertility in aging layer breeder roosters. ARE, antioxidant responsive element; CAT, catalase; GSH-Px, glutathione peroxidase; ERK, extracellular signal-related kinase; JNK, c-Jun N-terminal kinase; SOD, superoxide dismutase. 